\title{
PLASMAPHERESIS EDEMA. I. THE RELATION OF REDUC- TION OF SERUM PROTEINS TO EDEMA AND THE PATHOLOGICAL ANATOMY ACCOMPANYING PLASMAPHERESIS ${ }^{1}$
}

BY DANIEL C. DARROW, EDWARD B. HOPPER, AND M. KATHARINE CARY

(From the Department of Pediatrics, Yale University School of Medicine, New Haven)

(Received for publication March 14, 1932)

Almost forty years ago, Starling (1) measured the osmotic pressure of serum protein and showed that exchanges of fluid between the blood plasma and interstitial spaces could be explained by the diminution of the capillary hydrostatic pressure of blood in passing from the arteries to the veins and the osmotic pressure of the proteins. Krogh (2) has elaborated this idea and given more precise measurements of the factors governing the physiology of the capillaries.

Clinical application of the physiological principles involving exchange of water across the capillaries has been surprisingly slow. Starling's conception of the exchange of water between the blood and interstitial spaces would seem to have occurred to Bright (3) and some such idea was definitely proposed by Sabatier (4) and Solon (5) about a hundred years ago. Although many writers seem to have appreciated the physiological rôle of serum proteins until the end of the nineteenth century, for a time their function was forgotten. However, Epstein (6) seems to have been the first to emphasize that edema of nephritis and nephrosis could be explained by the low serum protein concentration. Govaerts (7), Schade and Claussen (8), v. Farkas (9) and others have made numerous measurements of the osmotic pressure of serum proteins and have shown that edema in renal disease is regularly accompanied by low serum protein concentration and low colloidal osmotic (oncotic) pressure, while in edema of heart disease not accompanied by proteinuria there is usually a high venous pressure.

The association of edema with low serum protein concentration is now well established (Peters, Wakeman, Eisenman and Lee (10), Van Slyke et al. (11) and others). Govaerts and v. Farkas found that a one per cent solution of albumin exerts about three times as great an osmotic pressure as a one per cent solution of globulin. This explains the fact that, in

${ }^{1}$ Part of the data in this paper was taken from the thesis of E. B. Hopper, done in partial fulfillment of the requirement for the degree of Doctor of Medicine in Yale University School of Medicine. A preliminary report was read before the Philadelphia Pediatric Society, May 14, 1929. 
edema due to low oncotic pressure, the albumin fraction of the plasma protein is usually low. At present it appears that albumin-deficit is the chief cause of the edema occurring in nephritis, nephrosis, nutritional edema and cachectic states.

Kohman (12) by feeding rats a diet low in protein, produced edema, which has been shown by Frisch, Mendel and Peters (13) to be accompanied by low concentration of serum protein. Shelburne and Egloff (14) have produced edema in a dog by feeding a low protein diet for a period of three months and then on observing a low serum protein concentration administering physiological saline by gavage. The type of experiments to be reported were first successfully carried out by Leiter (15) but similar work was started independently at about the same time by Barker and Kirk (16) and ourselves. Weech and Snelling (17) have recently performed similar experiments and will publish data showing the relation of the concentration of plasma proteins to chloride and sodium metabolism. The results of these groups of workers show that edema may be produced by reducing the content of plasma protein by repeatedly bleeding dogs, each time returning to the circulation the cells suspended in saline after removal of the plasma. The data of the various laboratories confirm and supplement each other and give a fair idea of the picture of experimental edema produced in such a fashion.

\section{METHODS}

Dogs were bled by puncture of the femoral artery, except in the first experiment. In this case, eleven bleedings were obtained from the jugular veins. The blood was collected in enough three per cent sodium citrate to give a final solution of about 0.3 per cent. The blood was centrifuged in $250 \mathrm{ml}$. centrifuge tubes and the plasma removed by suction. The centrifuge tubes were calibrated to permit rough but comparable estimations of the per cent by volume of red cells. The separated red cells, suspended in a 0.9 per cent solution of sodium chloride, were injected into the jugular veins. The succeeding bleeding was performed in most instances before returning the suspended cells, so as to increase the amount of plasma protein removed. In washing the cells into the veins, it was usually necessary to inject an amount of salt solution in excess of the amount of plasma removed. This excess is designated on the charts as extra I.V. saline. When the plasma proteins had reached a low level, physiological saline solution was given by gavage in order to have enough of this salt available to produce a large amount of interstitial fluid. Blood samples were withdrawn under liquid petrolatum in the morning before the first bleeding; that is, about eighteen hours after the previous bleeding or saline gavage.

The total protein was estimated in duplicate on one $\mathrm{ml}$. of serum by the macro-Kjeldahl method, using 30 per cent hydrogen peroxide to 
facilitate complete oxidation. Albumin was determined by the Howe (18) method of precipitating globulin with $\mathrm{Na}_{2} \mathrm{SO}_{4}$ in the first two experiments and in the third experiment up to the eighth day. Thereafter Howe's method, using a mixture of $\mathrm{KH}_{2} \mathrm{PO}_{4}$ and $\mathrm{K}_{2} \mathrm{H} \mathrm{PO} 4(1: 2)$ to precipitate the globulin, was used in the majority of the determinations. The change in method was made because the globulin dropped so low in a rather unexpected manner, in Experiment III. Essentially identical results were obtained for three days in Experiment III and also on a number of specimens of human serum by both the sodium sulphate and the phosphate precipitation of globulin. In general, in our hands, the phosphate precipitation gives more uniform results from day to day on the same patient and does not give the occasional wide fluctuations that seem most likely to be due to errors in the method. However, in most cases the two methods give essentially the same results. In our opinion the methods of precipitation of globulin are all probably inaccurate and data involving globulin and albumin determinations must be used with caution. However, there seems to be good reason to believe that there are at least two fractions of serum proteins having quite different functions.

The present work is divided into two parts: (1) The relation of serum protein to edema and the anatomical changes produced by plasmapheresis; and (2) the chemical pattern of the blood produced by plasmpheresis. The first phase of the work is given in this paper and the second phase in the subsequent paper in this Journal.

The essential data are presented in the accompanying charts of Experiments I, II, III, IV, and V. The upper lines represent the concentrations of total protein, albumin and globulin in the serum. The lower lines represent the weights of the dogs and the total osmotic pressure of the serum proteins. These oncotic pressure values were calculated by multiplying the per cent of albumin by 5.6 and the per cent of globulin by 1.45 . These are the factors given by Govaerts (7) for the conversion of concentrations of albumin and globulin to the osmotic pressure which they exert. The figures below represent the volume of the bleedings, the amount of 0.9 per cent saline which was injected above the amount necessary to replace the plasma removed, and the amount of 0.9 per cent salt solution given by gavage. Although corrected for the volume of citrate, the figures for the per cent by volume of erythrocytes are only approximate. At the top of the charts the amount of edema is represented by +- when the skin in dependent parts felt rather doughy, but there was no definitely pitting edema; + when there was pitting edema, and ++ when there were pitting edema and definite signs of ascites. At the end of the paper additional observations are recorded concerning each experiment. These notes are not complete protocols, but, together with the charts, report the facts that seem significant. 


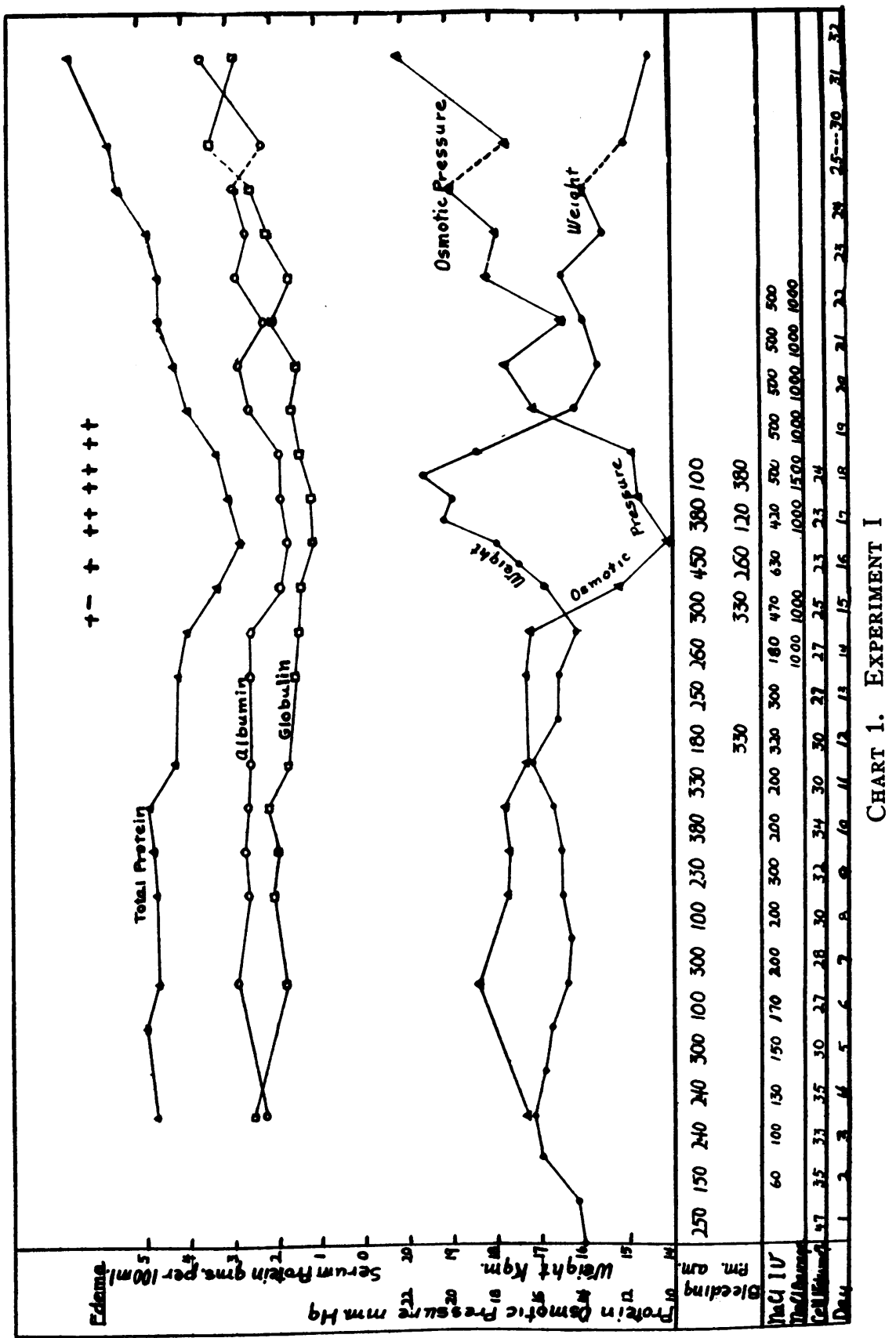


One would like to know the level of protein which is necessary for the production of edema. This can not be determined precisely from the data of these experiments. After a given bleeding and transfusion of cells suspended in saline solution, the plasma protein content was very low. However, the content rose fairly rapidly and reached the level

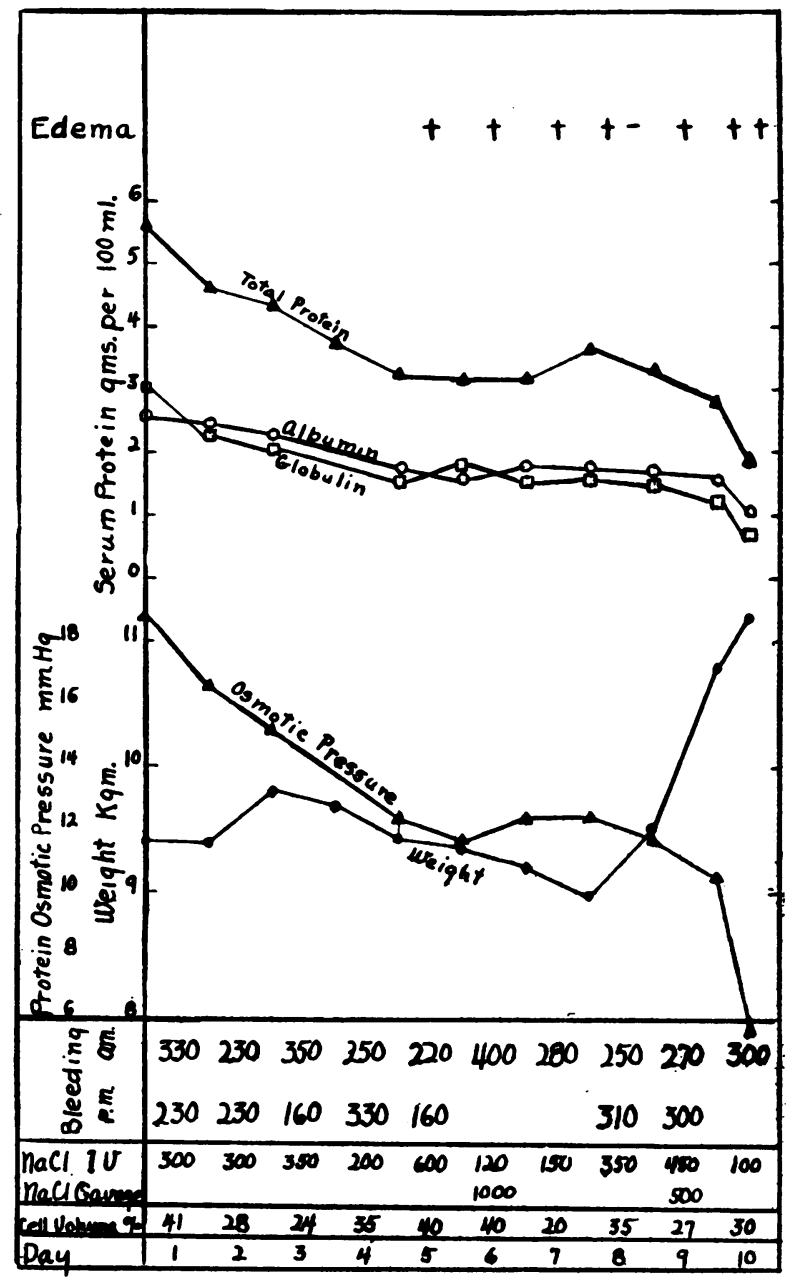

Chart 2. Experiment II

reported about eighteen hours later. Since the direction of water exchange is the best measure of the tendency to the formation of edema, an increase in weight is probably the best available evidence that the conditions necessary for edema production were present. However, at the time of taking the blood samples, the proteins may have reached already a level which would ultimately lead to a disappearance of edema. 
Therefore, the morning level of protein that was accompanied by increase in weight and edema represents a figure probably somewhat higher than that which would be found if one could devise experiments which would lead to a constant low level of plasma protein.

Bearing in mind the above considerations, the data are fairly consistent. Edema tended to appear when the total protein concentration fell below 3.5 to 3.0 per cent. As one might expect from the fact that a given

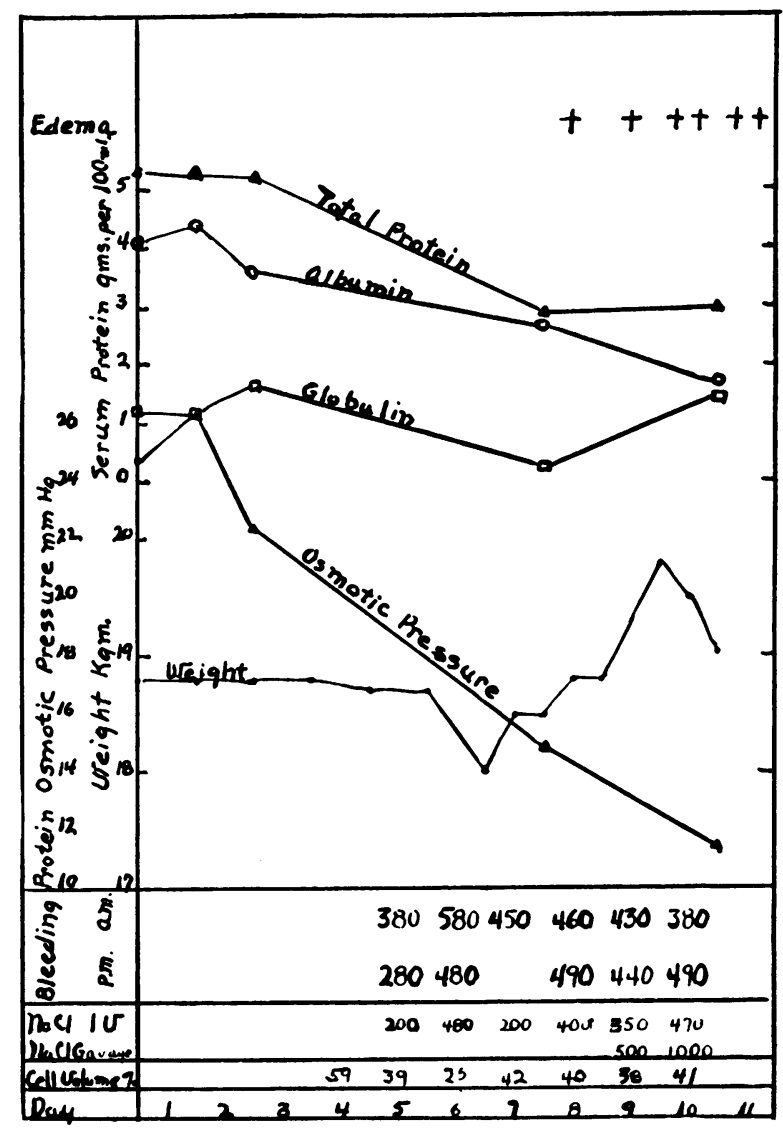

Chart 3. Experiment III

concentration of albumin has about three to four times as great osmotic pressure as the same concentration of globulin, the occurrence of edema is more closely related to the concentration of albumin than to the concentration of total protein. Thus edema occurred in all cases when the serum albumin concentration was below two per cent and was increasing when the albumin concentration was lower than 1.5 per cent. As the concentration of the serum albumin approached two per cent there was either questionable edema or a tendency to retention of water, as exhibited 


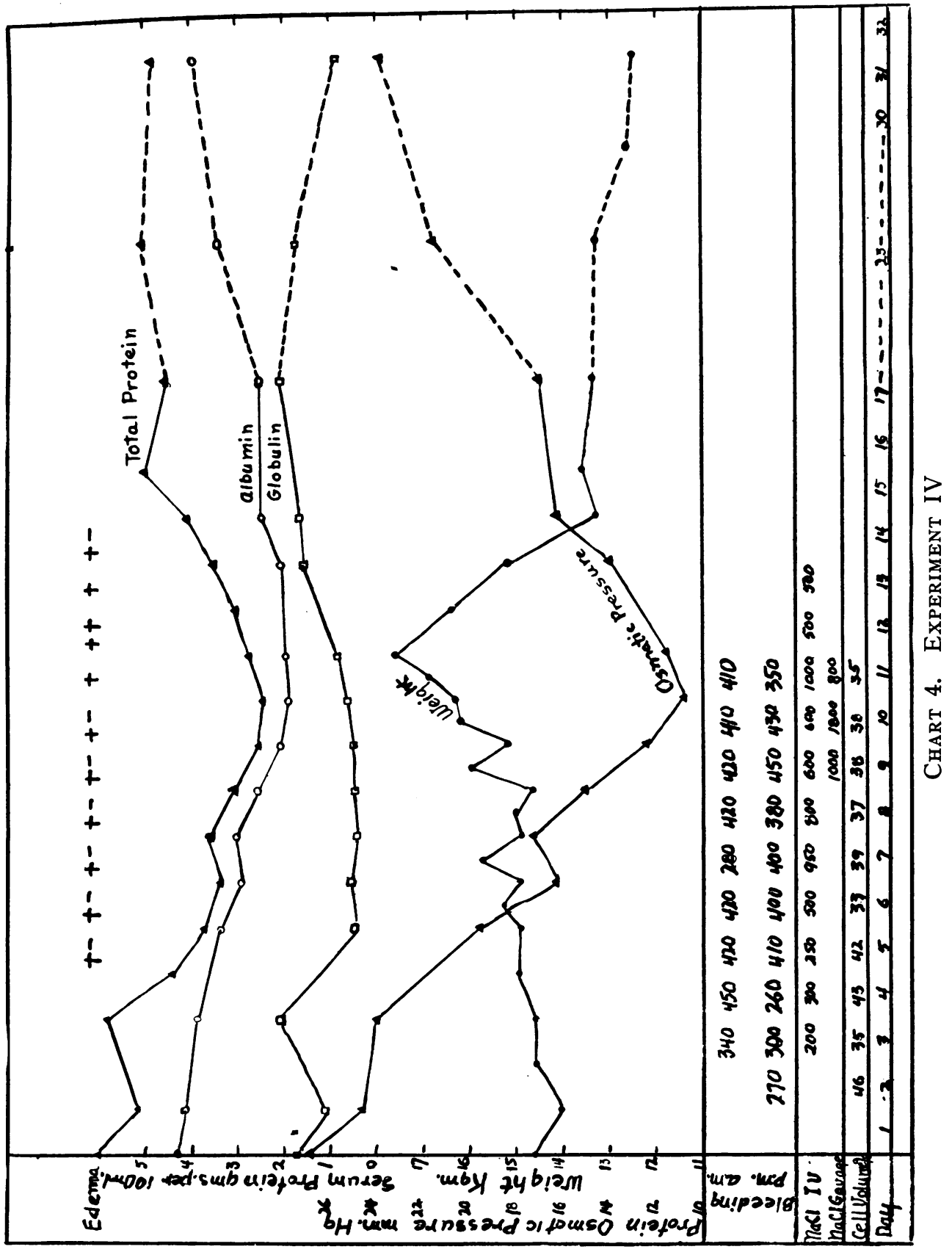


by an increase in weight in the afternoon. The dogs were weighed morning and afternoon but the afternoon weight is not recorded on the charts except where it differed significantly from the morning weight. Experiment IV illustrates well the greater importance of albumin. In this case the total protein concentration was below 3.0 per cent for two days and

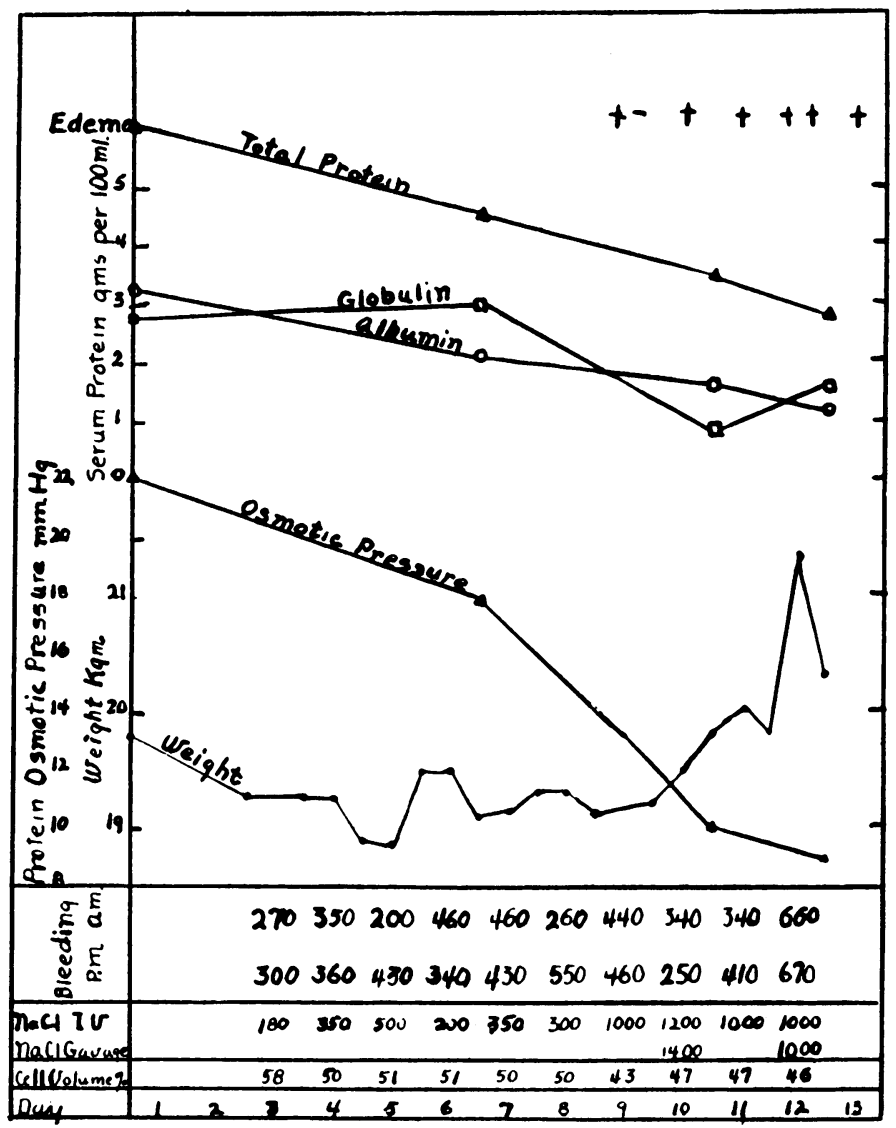

Chart 5. Experiment V

below 4.0 per cent for five days, but edema did not appear until the albumin had reached the critical level of 1.8 per cent.

The occurrence of edema should be more closely related to the total osmotic pressure of albumin plus globulin than to the concentration of albumin or of total protein. The line representing the osmotic pressure of the proteins demonstrates that this is the case. Edema seems to occur regularly when the osmotic pressure of the proteins drops below 11 to 12 $\mathrm{mm}$. of mercury.

Presumably the large amounts of 0.9 per cent saline given by gavage and injected intravenously aggravated the edema. Clinically it is 
recognized that $\mathrm{NaCl}$ is not the cause of edema but merely provides the chief ions of interstitial fluid and hence allows the body to increase the amount of interstitial fluid without greatly disturbing the electrolyte equilibrium existing between cellular and extracellular fluid. In Experiment I a liter of 0.9 per cent saline was given by gavage and $500 \mathrm{ml}$. was injected intravenously on each of the four days following the interruption of the bleeding. Nevertheless, the edema decreased rapidly. In Experiment IV, the intravenous injection of saline was continued two days after the bleeding and again the edema disappeared promptly. These experiments seem to prove that $\mathrm{NaCl}$ did not play a primary rôle in the production of the experimental edema.

The plasmapheresis reduced the albumin and globulin in about the same proportions. This fact may be appreciated best by examining Charts 6,7 and 8. In these charts, the serum protein, serum albumin and serum globulin are charted as per cent of their values before bleeding was started. In Experiments I, II and V the concentrations of total protein, albumin and globulin, were all reduced in the same proportions while the bleeding was being continued. In Experiment IV the globulin seems to have been reduced a little more rapidly than the albumin. This result may be due in part to difficulty in the precipitation of the globulin in the two specimens taken before the bleeding. An average of the two values was taken in constructing the charts, but if the lower value had been used, the total protein, albumin and globulin lines would have been more nearly parallel. In any case, the globulin was very low during the period of rapid depletion of the plasma proteins and a small error in the determination of total protein and albumin would have a relatively large effect on the globulin, since this latter is determined by difference. For this reason, Experiment IV, in conjunction with the other experiments, seems to indicate that the total protein, albumin and globulin are reduced in about the same proportions during rapid plasmapheresis.

In Experiments I and IV it is clear that after the bleeding is stopped the globulin recovers its previous concentration more rapidly than albumin. After about a week the globulin is normal or above normal. The albumin does not reach its normal concentration until two to three weeks after the plasmapheresis has been discontinued. If the globulin goes above the normal value, it tends to return to the normal value at about the same time as does the albumin.

Barker and Kirk (16) report a more rapid reduction of albumin than globulin. Indeed in some of their experiments the globulin was above the normal level at the time edema appeared. They found the albumin level for the production of edema to be one per cent. A similar critical level for human subjects is indicated by a small number of cases reported in their paper. 


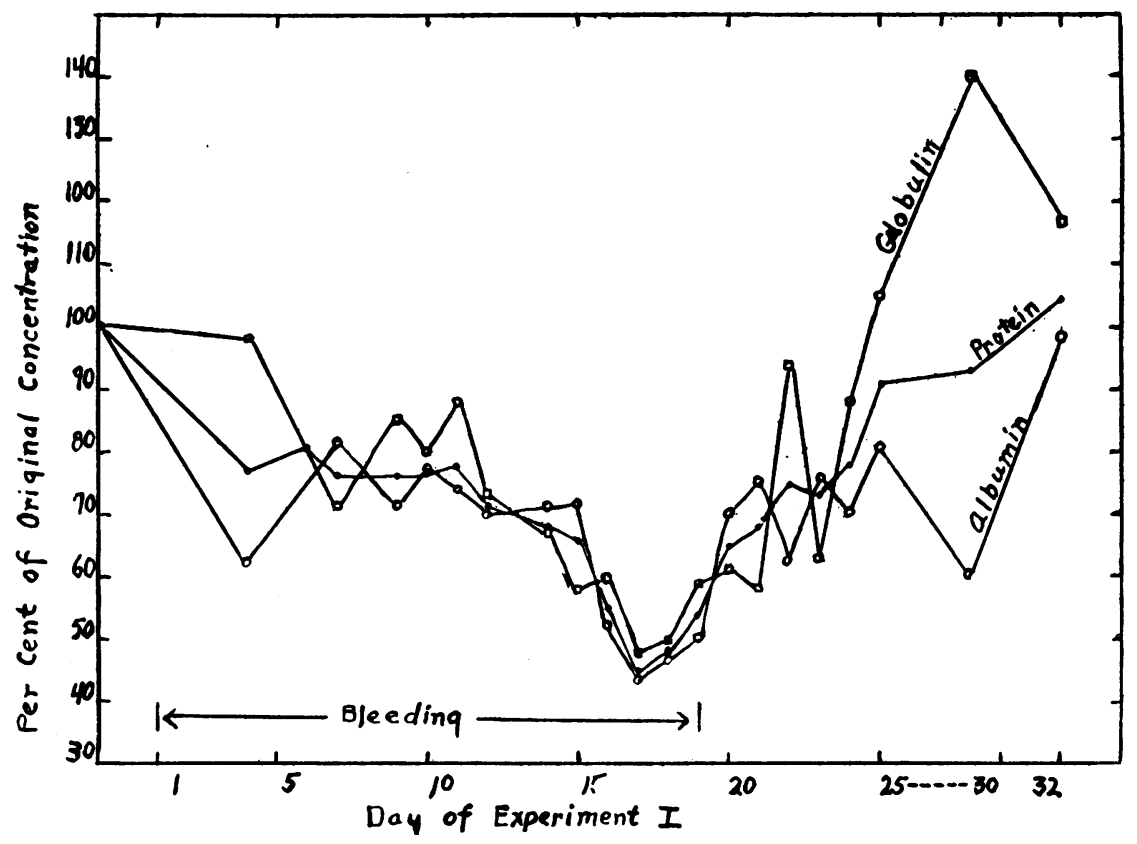

Chart 6

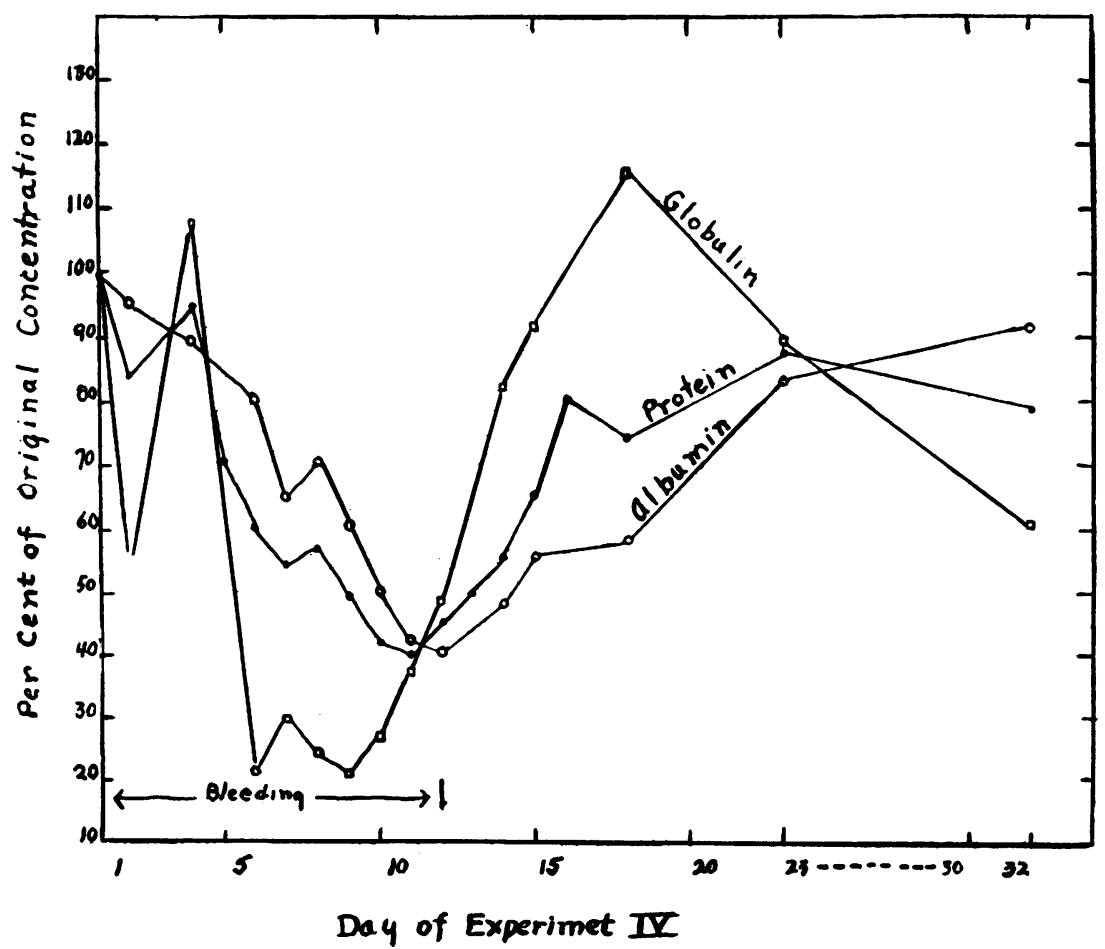

Chart 7 
The discrepancy between their results and ours is apparently due to some difference in method in the precipitation of globulin. Both before and after bleeding, their globulin concentrations are higher than ours. The same may be said of their values for globulin in patients with edema. However, it should be pointed out that since the dogs studied by Barker and Kirk were bled over a longer period of time, they might have had a greater opportunity to develop a change in the relative concentrations of albumin and globulin, due to the difference in the rate of regeneration of the two protein fractions. In the experiments reported by them there seems to be a more rapid reproduction of globulin, which might explain

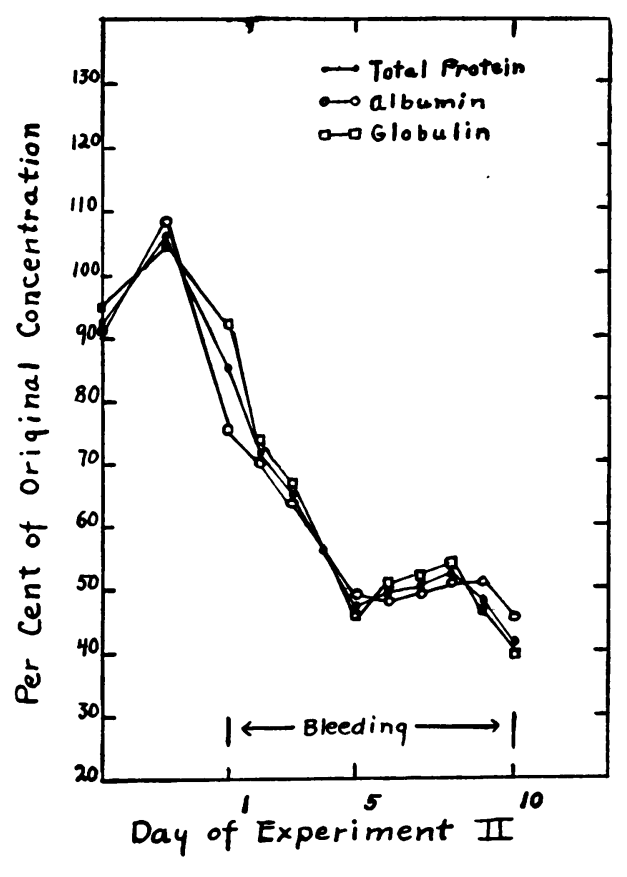

Chart 8

in part the relatively higher globulin concentration at the time of appearance of edema. Furthermore, Leiter (15) shows that globulin returns to the circulation more rapidly than albumin. Our figure for the critical level of albumin is in agreement with that of Leiter (15) and Weech and Snelling (17); it is somewhat lower, as one would expect, in dogs than in man, but is more consistent with the level found in other laboratories for human beings. Peters, Wakeman, Eisenman and Lee (10) found the critical level for albumin to be two per cent, while Van Slyke and many others (11) obtained a figure of 2 to 2.5 per cent. 


\section{Pathological anatomy of dogs rendered edematous by plasmapheresis}

Barker and Kirk (16) and Barker (19) examined the kidneys of dogs with low concentration of serum proteins resulting from plasmapheresis. In those dogs killed in about two weeks, the kidneys were swollen and microscopically showed marked cloudy swelling, some desquamation of the epithelium and extrusion of cellular nuclei. After about two months, the kidneys were normal in gross appearance, but atrophy of the tubular epithelium was evident microscopically. "At six months the gross changes were pronounced. The capsule stripped easily but left a roughened and dimpled surface. The cortex was greatly narrowed and appeared marked with greyish-white streaks. Microscopic examination revealed marked scar-tissue replacement in the inner half, producing dimpling. There was great increase in the tubular degeneration, fatty infiltration and glomerular atrophy over that seen earlier in the process." Barker and Kirk thought the low concentration of the plasma proteins might be the effective cause of tubular degeneration and even glomerular atrophy, when long continued.

Leiter (15) examined a number of kidneys of dogs subjected to plasmapheresis. He was unable to substantiate Barker and Kirk. Such lesions as he saw were thought to be a spontaneous nephritis which occasionally occurs in dogs.

In the present study, one dog was killed after ten days of plasmapheresis, another after six days, and a third one after ten days. The last dog was used in both Experiments IV and V but almost a year elapsed between the two studies and the dog was in excellent condition before the second period of plasmapheresis.

We find considerable difficulty in interpreting our own histological findings. Grossly the organs appear normal. The sections of the kidneys show no scarring nor cellular infiltration. The glomeruli are normal. The convoluted tubules do not show sharp cellular outlines; the cytoplasm stains pink with hematoxylin and eosin and is rather coarsely granular. The nuclei appear essentially normal. In places the lumina of the tubules are filled with pink staining granular material. The picture is that of rather marked cloudy swelling. Such a change is frequent at autopsies on human beings and little significance is attached to the finding. However, the fact that the dogs were killed and the tissue immediately fixed with Zenker's fluid, makes one hesitate to disregard the cloudy swelling entirely.

The liver capillaries are dilated and the liver cells appear smaller than normal. There is some granular detritus between the liver cells and capillaries. The appearance approximates that described by Wolbach and Blackfan (20) in cases of nephrosis. The sections of the heart, adrenals and spleen show no significant changes. 
The histological picture was controlled by examining two dogs subjected to the same procedures except plasmapheresis. In one dog, weighing $9 \mathrm{kgm}$., $500 \mathrm{ml}$. of 0.9 per cent $\mathrm{NaCl}$ were injected in travenously and $700 \mathrm{ml}$. of 0.9 per cent $\mathrm{NaCl}$ given by gavage for four days. On the fifth day one liter of salt solution was given intravenously and by gavage. On the sixth day the dog was killed with chloroform and the organs examined. Nothing abnormal was found grossly. The kindeys showed cloudy swelling just as pronounced as that of the dogs subjected to plasmapheresis. The liver cells were loaded with fat, but otherwise normal. The other tissues appeared normal microscopically. The other dog showed similar findings. The authors feel that any changes noted in the kidneys of the dogs subjected to plasmapheresis may be due to the large amounts of saline injected intravenously and given by gavage.

The changes in the kidneys are of a nature generally considered as reparable and, even if they are in part dependent on low concentration of serum protein, should not lead to permanent renal damage. Indeed, even in cases of "pure nephrosis," the kidneys show, for the most part, only a very marked cloudy swelling and some fatty changes in the tubules. Wolbach and Blackfan (20) felt that the lesions they found in the tubules were capable of repair in all but the most extreme instances. There seems to be little justification for assuming that low concentration of plasma protein is a cause of permanent renal injury in nephrosis or hydropigenous nephritis.

On several occasions urine was examined for albumin, sugar, casts and cells. Nothing suggesting renal injury was found. At the autopsies in Experiments II and III, the urine contained almost fifteen grams per liter of chloride expressed as $\mathrm{NaCl}$. This finding indicates excellent ability to concentrate chlorides. Barker and Kirk (16) report occasional proteinuria and cylindruria. This occurred after several weeks of bleeding and was transient.

The analogy between the state of the dogs with low plasma protein concentration and cases of nephrosis, nutritional edema and cachectic states with edema is fairly close. In all, the production of edema is mainly dependent on low concentration of plasma albumin. In all, the edema fluid is practically free of protein. In all, symptoms of undernutrition appear. Barker and Kirk found a low basal metabolic rate, which is frequently encountered in nephrosis as well as in starvation edema. We were impressed with the loss of weight accompanying plasmapheresis when there was no edema, as were Leiter (15) and Barker and Kirk (16). All the dogs tended to have loose stools during the edematous phase and in Experiments $I$ and IV, this amounted to a moderate diarrhea. In Experiment I, the diarrhea occurred at a time when salt solution was being given by gavage, but in Experiment IV, the most marked diarrhea occurred on the thirteenth day when salt 
solution had not been given by mouth for forty-eight hours. The loose stools would, therefore, seem to be part of the mechanism for getting rid of the large amounts of interstitial fluids during the period of recovery from edema. Similar observations have been fairly frequent in those cases of nephrosis which we have seen.

In the succeeding paper it will be pointed out that the chloride concentration of the serum tends to be high, as is also the case in clinical instances of edema with low concentration of serum protein.

\section{SUMMARY}

(1) Five dogs were bled and the cells reinjected after removal of the plasma proteins. By this procedure the albumin and globulin were reduced in approximately the same proportions. After the bleeding was stopped the restoration of globulin was more rapid than that of albumin.

(2) There seemed to be a critical concentration of 3 to 3.5 per cent total plasma protein at which edema appeared. The critical concentration of 1.5 per cent albumin seems to determine the production of edema more regularly than the total protein concentration. The occurrence of edema is most closely associated with a total protein osmotic pressure below $12 \mathrm{~mm}$. of mercury, when the protein osmotic pressure is calculated according to Govaerts (7).

(3) Microscopic examination of the tissues of three dogs killed during the edematous phase revealed marked cloudy swelling of the tubular epithelium of the kidneys, but no lesions that did not seem readily reparable. The liver showed rather marked dilation of the capillaries and the liver cells were small and rather granular. Sections from heart, adrenal and spleen revealed no lesions. Similar cloudy swelling of the kidneys occurred in dogs subjected to the intravenous injection of saline and the administration of salt solution by gavage. In our opinion a low concentration of plasma protein is not a significant cause of permanent renal damage.

\section{CONCLUSIONS}

Dogs rendered edematous by plasmapheresis show a type of edema closely analogous to that of cases of nephrosis, hydropigenous nephritis, nutritional edema and cachectic states. Low plasma protein should not be considered a cause of permanent renal damage.

\section{PROTOCOLS}

Experiment I. Healthy adult male Airedale. The first eleven bleedings were obtained from jugular veins. Thereafter all bleedings were from femoral arteries. On the following days blood was lost: first day about $150 \mathrm{ml}$. through clotting; twelf th day about $100 \mathrm{ml}$. through clotting; and fifteenth day about $125 \mathrm{ml}$. through breaking of a centrifuge tube. The dog's appetite was poor from the tenth to the twentieth day of the experiment. During the period of 
marked edema the dog seemed fairly well but was listless. There was evidence of weakness and nausea after the larger bleedings of the fifteenth and sixteenth days. The stools were loose during the edematous period and there was moderate diarrhea on the twenty-first day. The appetite returned quickly when the bleeding was stopped. The dog lost body tissue during the experiment, as was evidenced by his appearance and weight after recovery.

Experiment II. Rather small, healthy mongrel collie. All bleedings were from femoral arteries and transfusions into jugular veins. An attempt was made to feed the dog a diet high in fat and carbohydrate and low in protein, made up of a known mixture of casein, lard, dextrine, salts and vitamins. This led to visible lipemia during the first days but after the fourth day the dog refused to eat and the lipemia disappeared. He was then given the kennel diet of dog biscuit and a little meat, of which he likewise refused the greater part. About $150 \mathrm{ml}$. of blood was lost through clotting on the first day. This dog showed considerable weakness and nausea and his veins seemed collapsed after each bleeding. On the fifth day he was transfused with about $80 \mathrm{ml}$. of compatible erythrocytes from another dog. On the fifth and sixth days the transfusions were given before, rather than after, the bleeding. On the tenth day the transfusion was thought to be going into the lower part of the jugular vein; but it was discovered later that most of it had infiltrated the neck and mediastinal tissues. The dog remained weak and had difficult, rather rapid deep breathing which suggested acidosis. Although he seemed to be recovering at $8 \mathrm{P} . \mathrm{M}$. he was so uncomfortable that he was killed with chloroform after the removal of clear abdominal fluid and samples of arterial and venous blood.

At this time there was marked pitting edema of the chest walls and legs and shifting dullness in the abdomen.

Postmortem urine-Acid reaction. No reaction for protein or sugar. Microscopically no casts, erythrocytes or leukocytes. Chloride 14.95 grams. $\mathrm{NaCl}$ per liter.

Autopsy-The abdomen contained about $500 \mathrm{ml}$. of a slightly cloudy, colorless fluid. Together the chest cavities contained about $750 \mathrm{ml}$. of similar fluid which contained some red cells which had apparently come from the mediastinum. The mediastinum and lower tissues of the neck were infiltrated with blood from the misdirected transfusion. The trachea may have been compressed by this fluid. Viscera were normal grossly.

Microscopic sections of the liver, spleen and heart were essentially normal, except for slight cloudy swelling. The kidney sections are discussed elsewhere.

Experiment III. Large, fat Airedale, rather old in appearance. All bleedings were from femoral arteries and transfusions into jugular veins. This dog seemed to be more affected by the bleedings than the other dogs. After the bleedings he usually exhibited nausea, spasmodic movements of the abdominal muscles and diaphragm. He vomited on the sixth, ninth and tenth days. On the eleventh day, having eaten little since the seventh, he was listless, but otherwise he acted fairly normally. He showed pitting edema in the loose skin around the Achilles' tendon and the subcutaneous tissue elsewhere felt boggy. Arterial and venous samples were obtained and the dog was then killed with chloroform and abdominal fluid obtained after opening the peritoneum. Postmortem urine contained 14.8 grams $\mathrm{Cl}$ as $\mathrm{NaCl}$ per liter. The urine gave no reaction for protein or sugar and showed no abnormality microscopically.

Autopsy-Nothing remarkable was found grossly, except edematous subcutaneous tissues, about $400 \mathrm{ml}$. of slightly cloudy, colorless abdominal fluid 
and about $75 \mathrm{ml}$. of similar fluid in each chest cavity. Microscopic sections of the heart, lungs, spleen and liver were essentially normal except for slight cloudy swelling. The kidney sections are discussed elsewhere.

Experiment $I V$. Healthy female German shepherd. All bleedings were from femoral arteries and transfusions into jugular veins. All samples were taken before bleeding in the morning. On the fourth day the dog vomited after each bleeding. The dog showed weakness and nausea after several of the larger bleedings, but seemed to feel well after being transfused. From the sixth to the twelfth day the appetite was poor. The stools were loose during the edematous phase. There was moderate diarrhea on the thirteenth day when the edema was clearing. On the twelfth day this dog was more edematous than any of the other animals. She showed marked pitting edema of the back, chest walls, front and hind legs. There was bulging of the flanks, shifting dullness in the abdomen, and considerable dyspnea, apparently due to chest fluid. The dog was somewhat apathetic and was not interested in food, but otherwise did not seem ill. She was lively the next day and apparently normal in two days. However, she became very thin during the next two weeks.

Experiment $V$. Healthy female German shepherd. This was the same dog used in Experiment IV. Almost a year had elapsed since Experiment IV and she was in better physical condition for the second than the first experiment. All bleedings were from femoral arteries and transfusions into jugular veins. Bleedings caused little or no symptoms. At 6 P.M. of the twelfth day, definite pitting edema of the hind legs and abdominal wall and shifting dullness of the flanks were found. The next morning the shifting dullness of the abdomen was gone, but there was still moderate edema of the abdominal wall and hind legs. Arterial and venous samples of blood were taken and several unsuccessful attempts were made to obtain abdominal fluid. The dog was killed with chloroform.

Autopsy-Nothing abnormal was found grossly except edema of the subcutaneous tissues and about $50 \mathrm{ml}$. of slightly blood tinged fluid in the abdominal cavity. The blood undoubtedly came from the attempts to obtain abdominal fluid just before killing the animal. Microscopic sections of the heart, spleen, liver, adrenals and kidneys were essentially negative, except for slight cloudy swelling of the liver and kidneys. The kidney sections have already been discussed in detail.

\section{BIBLIOGRAPHY}

1. Starling, E. H., J. Physiol., 1895, xix, 312. On the Absorption of Fluids from the Connective Tissue Spaces.

2. Krogh, A., The Anatomy and Physiology of Capillaries. Yale University Press, New Haven, 1929.

3. Bright, R., Reports of Medical Cases. London, 1927, Vol. 1.

4. Sabatier, J. C., Arch. Génerales de Med., 1834, V (2nd série), 333. Considérations et Observations sur l'hydropisie Symptomatique d'une lesion speciale des reins.

5. Solon, Martin, De l'Albuminurie ou hydropisie causée par maladie des reins; modifications de l'urine dans cet état morbide à l'époque critique des maladies aiguës et durant le cours de quelques affections bilieuses. Bechet Jeune, Paris, 1838.

6. Epstein, A. A., Am. J. Med. Sci., 1917, cliv, 638. Concerning the Causation of Edema in Chronic Parenchymatous Nephritis: Method for its Alleviation. 
7. Govaerts, P., Bull. Acad. roy. de méd. de Belgique, 1924, iv, 161. Recherches cliniques sur le rôle de la pression osmotique des proténes du sang dans la pathogénie des oedèmes et de l'hypertension artérielle.

Govaerts, P., Bull. Acad. roy. de méd. de Belgique, 1927, vii, 356. Influence de la teneur du sérum en albumines et en globulines sur la pression osmotique des protéines et sur la formation de oedèmes.

8. Schade, H., and Claussen, F., Ztschr. f. klin. Med., 1924, c, 363. Der onkotische Druck des Blutplasmas und die Entstehung des renal bedingten Ödems.

9. v. Farkas, G., Ztschr. f. d. ges. exp. Med., 1928, lxii, 35. Ist das Ödem ein Resultat der Capillarsekretion?

v. Farkas, G., Ztschr. f. d. ges. exp. Med., 1927, liii, 666. Studien über den kolloidosmotischen Druck des Serums.

10. Peters, J. P., Wakeman, A. M., Eisenman, A. J., and Lee, C., J. Clin. Invest., 1929, vi, 577. Total Acid-base Equilibrium of Plasma in Health and Disease. XII. A Study of Renal Edema.

11. Van Slyke, D. D., Stillman, E., Möller, E., Ehrich, W., McIntosh, J. F., Leiter, L., MacKay, E. M., Hannon, R. R., Moore, N. S., and Johnson, C., Medicine, 1930, ix, 257. Observations on the Courses of Different Types of Brights Disease and the Resultant Changes in Renal Anatomy.

12. Kohman, E. A., Am. J. Physiol., 1920, li, 378. The Experimental Production of Edema as Related to Protein Deficiency.

13. Frisch, R. A., Mendel, L. B., and Peters, J. P., J. Biol. Chem., 1929, lxxxiv, 167. The Production of Edema and Serum Protein Deficiency in White Rats by Low Protein Diets.

14. Shelburne, S. A., and Egloff, W. C., Arch. Int. Med., 1931, xlviii, 51. Experimental Edema.

15. Leiter, L., Proc. Soc. Exp. Biol. and Med., 1928, xxvi, 173. Experimental Edema.

Leiter, L., Proc. Soc. Exp. Biol. and Med., 1930, xxvii, 1002. Experimental Edema-Further Observations on the Plasma Proteins and Blood Cholesterol.

Leiter, L., Arch. Int. Med., 1931, xlviii, 1. Experimental Nephrotic Edema.

16. Barker, M. H., and Kirk, E. J., Arch. Int. Med., 1930, xlv, 319. Experimental Edema (Nephrosis) in Dogs in Relation to Edema of Renal Origin in Patients.

17. Weech, A. A., and Snelling, C. E., Personal Communication.

18. Howe, P. E., J. Biol. Chem., 1923, lvii, 241. The Relative Precipitating Capacity of Certain Salts when Applied to Blood Serum or Plasma and the Influence of the Cation in the Precipitation of Proteins.

19. Barker, M. H., Proc. Soc. Exp. Biol. and Med., 1930, xxvii, 608. A Renal Lesion Following Plasmapheresis.

20. Wolbach, S. B., and Blackfan, K. D., Am. J. Med. Sci., 1930, clxxx, 453. Clinical and Pathological Studies on So-called Tubular Nephritis (Nephrosis). 